\title{
Grounding research projects in the undergraduate curriculum: assessment strategies
}

Angela Laycock

School of Law, University of Greenwich

\section{Introduction: research-based projects, grounded theory and the undergraduate curriculum}

In their 2009 paper, Developing Undergraduate Research and Enquiry, Mick Healey and Alan Jenkins observed, "The key to developing undergraduate research and inquiry is to mainstream it and integrate it into the curriculum for all students" (Healey \& Jenkins 2009, 6). The following case study gives an account of the steps taken to incorporate two research projects, one international and one community-based, into the final year undergraduate curriculum resulting in significant student success and programme development. Both used a grounded theory model. This led to the development of an assessment regime to achieve the dual aims of providing the student with the opportunity to learn through participatory research and, at the same time, furnishing the commissioner of the research with meaningful findings and recommendations.

The international project was entitled the Comparative Evaluation of Rights Mechanisms Project (CERMP) and was part of the Disability Rights Promotion International (DRPI) project, Building a Human Rights Monitoring System in the Field of Disability (2003-8). The role of the Greenwich team was to monitor the effectiveness of Disability Law in England and Wales. The community-based project was to report on the work of the Greenwich Association of Disabled People Centre for Independent Living (GAD) Advocacy Service and on access to justice for disabled people in Greenwich (2008-10). Using an account of two specific legal research projects, this case study sets out to demonstrate that the grounded theory approach on which they are based and their assessment regime could be utilised for any discipline aiming to introduce 'research-based' learning into the undergraduate curriculum. It is divided into three sections: in the first, the role of the research project as a teaching tool is considered; in the second, a grounded theory model for research projects in the undergraduate curriculum is proposed; and, in the final section, the practicalities of developing an assessment regime to achieve the dual outcomes of providing the stakeholder with useful research findings, and the student with an accurate and just assessment of his/her learning are explored. The study concludes that 'research-based learning' at first degree level is not only possible but is an essential part of undergraduate learning and offers the grounded theory approach as a method of achieving its incorporation in the undergraduate curriculum.

\section{The research-based project and grounded theory as teaching tools}

Healey and Jenkins identified "four main ways of engaging undergraduates with research and inquiry: 
research-led: learning about current research in the discipline; research-oriented: developing research skills and techniques; research-based: undertaking research and inquiry; research-tutored: engaging in research discussions" (1998:6).

Of the four types of learning, the incorporation of 'research-based learning' into the undergraduate curriculum, while providing the most effective teaching tool, is the most problematic. 'Research-tutored' and 'research-led' learning lend themselves to incorporation since they are largely library-based activities, while opportunities for 'research-oriented' learning - for example individual contributions to an in-house publication on an agreed theme - can be manufactured within a course programme for a larger cohort (Phillips, E., Clarke, S., Crofts S., and Laycock, A., 2009). The incorporation of 'research based' learning, on the other hand, is more problematic. Firstly, the logistics of setting up projects and arranging supervision for such learning is a complex operation and, secondly, because the duration of the project, confined within the parameters of the academic year and subject to university regulations for ethical approval, often precludes any involvement in commissioned research projects. Nevertheless, if it can be achieved, 'research-based learning' provides the most effective mechanism for deep learning - "the critical analysis of new ideas, linking them to already known concepts and principles...lead(ing) to understanding and long-term retention of concepts so that they can be used for problem solving in unfamiliar contexts" (Higher Education Academy 2013) - and the development of effective reflective practitioners. 'Research-based learning' shifts the focus to what the student does, rather than to what the student studies, and, as Anne Macduff observed, "Focusing on what the student does is more effective because it emphasises the importance of teaching practices that provide critical and personally engaging activities and deep learning. Moreover, deep social learning leads to a more sophisticated understanding of social issues and reaffirms the student's agency to act in the real world. Legal (and, for that matter, non-legal) educators have a responsibility to develop these critical skills in their students to enable more students to translate their understandings into actions beyond the lecture theatre."(Macduff, 2005, 135).

Such a framework for promoting "deep social learning" through "act(ing) in the real world" is provided by Anselm Strauss and Juliet Corbin's grounded theory philosophy, later adapted for interpreting and teaching law by the Southern African Womens' Lawyers (SAWLs). Strauss and Corbin defined grounded theory as "theory that was derived from data, systematically gathered and analyzed through the research process." "In this method," they go on to explain, "data collection, analysis and eventual theory stand in close relationship to one another." (Strauss and Corbin, 1998, 12). Rather than beginning with a preconceived theory, the researcher identifies an area of study, collects data from it and then develops a theory through his/her analysis of it. A theory derived in this way is more likely to "resemble the "reality"' than a theory based on experience or a notion of how things ought to work. "'Grounded theories", because they are drawn from data, are likely to offer insight, enhance understanding, and provide a meaningful guide to action." (Strauss and Corbin, 1998, 12). Thus, a student research project grounded in data collection and analysis should fulfil its dual function of producing research outcomes for the benefit of stakeholders while educating the student researcher. This is particularly true in the field of disability - the focus of the two 
projects referred to in this case study - where the lack of resources has meant that there has been relatively little collection of data and analysis or research.

\section{"Pursuing grounded theory" in England and Wales: adapting the model to integrate "research-based" learning into the undergraduate curriculum}

In their book, Pursuing Grounded Theory in Law: South-North Experiences in Developing Women's Law, the authors describe approaches that "assist students for higher degrees and undergraduates writing dissertations to come to grips with the research, analysis and writing process" (Hellum \& Stewart, 1998, 21). They define grounded theory as "an iterative process in which data and theory, lived reality and perceptions about norms are constantly engaged with each other to help the researcher decide what data to collect and how to interpret it." (Hellum \& Stewart, 1998, 18). At every stage in the research process, the researcher's assumptions lead to the collection of certain data, which, when analysed, will cause the researcher not only to adjust his/her assumptions but, more significantly, will suggest new avenues of enquiry and new sources of data. It, therefore, follows that the SAWL scholar can be identified as someone "likely to be engaged in efforts to investigate empirically and from this to generate critiques and arguments as to how judges, lawmakers and administrators could and, perhaps, should interpret or amend the law. Not only the so-called formal or state legal system has to be scrutinized but also other fora and mechanisms for dispute resolution and regulation need to be closely examined." (Hellum and Stewart, 1998, 25-6). In the SAWL model, students begin the course by giving legal advice and then monitor the effectiveness and relevance of the advice that they have offered in order to suggest a viable solution to the given problem. Frequently, the students find that their solutions founded on colonial or customary law are inadequate and what is needed is a change in society.

Alice Armstrong, one of the originators of SAWL, described grounded theory as a "marriage between the Women's Law perspective and the Legal Pluralism perspective." (Alice Armstrong interview 23.3.96, Laycock 1996). Faced with problems created by conflicts between colonial and customary law and between these recognised laws and actual custom and practice, the SAWLs adapted the methodology of Scandinavian Women's Law to analyse the content and effectiveness of particular law in specific areas relating to Family Law and, in so doing, they developed identifiable new principles about the nature of law: firstly, that custom and practices are a form of law in that they sometimes have greater force than that which is more generally recognised as law, and secondly, that "the law can be properly evaluated or appraised only if, in addition to understanding the intentions and the rationale behind the law, one also has an insight into the consequences of the law on individuals."(Maboreke, M.,1990). A postgraduate diploma course based on these principles was set up at the University of Zimbabwe in the early 1990s to train government officials, non-governmental organization (NGO) workers and legal practitioners in identifying "the gap" between "law and reality" and then "to bridge it" (Julie Stewart interview 23.3.96: Laycock 1996 (7)). In 1996, as part of my fieldwork for my masters' dissertation, I spent some time with the students on the Women's Law Diploma Course, who had just come back from researching into the law relating to domestic service in a suburb of Harare. They all felt that they had a much greater understanding of how the law, both formal and informal, operates in 
general. For example, Christopher Madrama, a government official from Uganda, commented that, as a result, he was far more aware that often solutions are not to be found with the law at all and that, when he returned to his post, he would be using the SAWL approach to initiate reforms to prevent the spread of AIDS.

The SAWL model itself was not suited to the English and Welsh LL.B curriculum for two reasons. Firstly, the undergraduates, by definition, could not match the postgraduates in confidence, competence and skills of inquiry that come, or should come, from having completed a first degree. Secondly, the United Kingdom is a highly legislated, litigious society. Consequently, though learning through giving legal advice might be a possibility given large insurance premiums and strict supervision by a qualified lawyer, it would not be practicable for students to learn by analysing the impact and relevance of the advice they had given. Without the opportunity for subsequent analysis, the result would be a very different type of learning from that achieved in the Southern African model: it would be 'clinical legal education' - "learning through participation in real or realistic legal interactions coupled with reflection on this experience" (Kerrigan \& Murray 2011, 5) - rather than 'research-based learning'-"research on the reconceptualization of law to take proper account of the needs of ... marginalized groups" (Hellum \& Stewart 1998, 24). The outcome of the former would be knowledge of current legal practice, while the outcome of the latter would be "to create these new concepts and deliver an effective way to address the needs of the groups on behalf of whom they argue" so that "change (can be) stimulated" (Hellum \& Stewart 1998, 24). I, therefore, have adapted the model by grounding the learning using a commissioned research team project to collect and analyse data in order to reconceptualise the law rather than in the giving of legal advice and monitoring its effect.

This grounding in commissioned research was essential in order to give the student a full understanding of his/her responsibilities as a researcher and confidence and opportunity to go beyond the traditional boundaries of undergraduate coursework. To provide such an opportunity the Comparative Evaluation of Rights Mechanisms Project (CERMP) team framework was developed. The timeframe of the project was negotiated with the commissioner of the research and was more than a year's duration. While the project leader was the same member of academic staff throughout, the project teams, consisting of a maximum of ten undergraduate researchers, were formed annually. Members of the new team took over responsibility for specific briefs each year to ensure continuity. The project team structure made it possible for undergraduates to acquire, through experience and at their own pace, research skills and competence in inquiry, while the project leader could ensure that professional and ethical standards were maintained.

\section{Parallel planning: assessment for research outcomes and integration into the undergraduate curriculum}

In order to integrate the CERMP into the undergraduate curriculum, it was necessary to satisfy the course validation panel that the assessment regime was on a par with that of other third year courses and that the outcomes identified for this third year undergraduate option would reflect its declared "dual aim of 
1. providing the student with the opportunity to learn through practical experience and participatory research the skills required to work as part of a research project team and

2. making a comparative study evaluating mechanisms for the promotion of the rights of a specific sector of society in the UK and at least one other jurisdiction." (CERMP course specification)

The assessment regime, therefore, had to be both formative and summative, providing the student with practical learning opportunities and the examiner and other stakeholders with opportunities to assess the outcomes of the research. As the Boyer Commission on Educating Undergraduates in Research Universities has observed, "Dissemination of results is an essential and integral part of the research process, which means that training in research cannot be considered complete without training in effective communication. Skills of analysis, clear explanation of complicated materials, brevity, and lucidity should be the hallmarks of communication in every course "(Boyer Commission 1998, 24). "Dissemination of results" and "training in effective communication" were achieved through two of the three assessment components, the presentation of the project's findings in a public arena and the presentation of a written report on the team's findings. The third component (adapted from postgraduate assessment) was a viva, which provided an opportunity for presentation of the data collected by the individual, and for reflection and evaluation of the project findings and research process. The presentation and report were equally weighted, each at $40 \%$ of the total mark, while the viva provided the remaining $20 \%$.

\section{The presentation}

Project teams have presented their findings in a variety of public fora, including public stakeholder meetings, academic and postgraduate conferences, and open seminars. A review of the Australian honours curriculum in 2011 reported that "a commonly cited aspect of the assessment process for many of the programs was oral presentation" and that "most coordinators reported the oral presentation as one of the highlights of their program" (Kiley, Boud, Manathunga \& Cantwell 2011,627). This has certainly been the experience of the Greenwich projects. The public nature of the examination has led to heightened performance. In 2009, for example, I made the following observation in the course Annual Monitoring Report (AMR): "All three gained first class for their presentations. As with previous years, the demands of a public forum - this year the School of Humanities and Social Sciences Research Conference - and the collegiate nature of the assessment served to raise the students' own expectations and consequently their standards."

In order to ensure transparency, the summative examinations were conducted by two independent examiners from the academic staff, who attended the public presentation, marked outcomes according to the university marking criteria and entered their comments on the Project Presentation Candidate Assessment Form. Supportive teamwork was reinforced through the division of marks for assessment: $60 \%$ of the marks being allocated for individual performance and $40 \%$ for the team's performance. Figure 1 provides an example of a completed presentation assessment form: the key criteria for individual performance being structure and communication of the individual's paper on his/her area of responsibility, use of material and identification of issue, each criterion accounting for $10 \%$ of 
the total mark while the criteria for the team as a whole is their effectiveness as a project team, their ability to promote discussion and to recognise each other's strengths and expertise.

Figure 1: Project Presentation Candidate Assessment Form

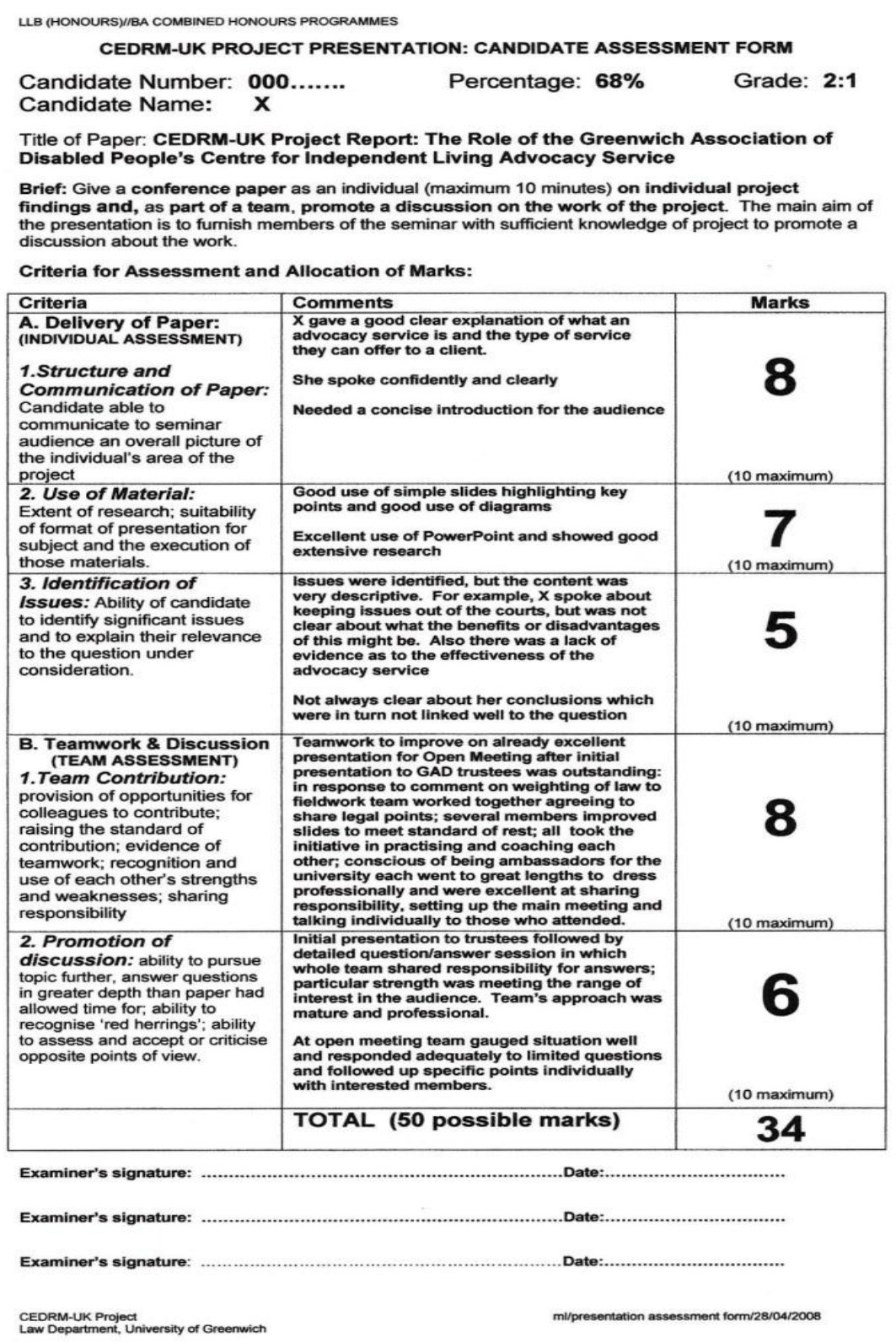

There is also a formative purpose to this assessment: the emphasis is on the process of preparation, compulsory elements of which are submission and editing of individual presentations and team workshops for the construction and honing of the individual parts into a whole team presentation and the acquisition of presentation skills. At every stage of this process, the project leader is a full team member working on perfecting the presentation and, if appropriate, will play a part in the public presentation. It is also formative because the 
students make use of the experience and the feedback from the audience when preparing their written assessment.

\section{The report}

The report component was designed to provide both an opportunity for the student to acquire skills in formal report writing and to serve as a source for the final report when the work of successive year teams is collated into the final project report. Here again, preparing a commissioned report tended to raise the students' performance in their desire to produce a professional outcome. As with the presentation, the assessment is both formative and summative with the project leader acting as editor/advisor during the production stage and only the final submission being formally assessed.

\section{The viva}

The viva was included in the assessment regime for two reasons: the first to do justice to the student to ensure that $\mathrm{s}$ /he could be accredited with all the research individually undertaken; the second to fulfil an aim of both the projects, the collation of data.

Without the vehicle of the viva, the undergraduate project team member would not have had the opportunity to share and discuss all of his/her data and to evaluate his/her personal contribution to the project. John Wellington's research into the postgraduate viva examination from a sample of students "mainly from the social sciences" but also "from law, architecture, landscape and management, (with a small number approximately $10 \%$ ) from the sciences and engineering", would suggest that "many if not all, students do want to experience a viva in which they will be challenged, be asked to articulate their work, to justify and clarify, to tell 'their story' and to engage in deep discussion, with 'experts' in their field.... We, as examiners and supervisors," he argues, "owe it to them to make it a worthwhile, engaging and formative event." (Wellington, 2011, 80).

The questions posed in the viva were given to the students in advance and were deliberately very simple:

1. Explain how you organised your folder.

2. Critically talk through your contribution to the whole project.

3. What have you learnt from doing the project: knowledge and methodology?

4. Where do you think the project should go from here?

They were designed to provide a framework for dialogue between the examiners and the student as well as an opportunity for critical reflection and for demonstrating a sense of ownership of the project. John Wellington and several other commentators have identified "the need for preparation": "The viva is an emotional experience for all students and, although this may sound very un-English, this emotional aspect needs to be considered and prepared for." (Wellington, 2011,83). Despite efforts to prepare students, a small minority lost marks because they did not treat the examination with sufficient respect. In the 2008-9 
AMR, for example, I noted a drop in standard in this assessment which I suggested "may be explained by less careful preparation".

As with the presentation, the examiners' observations and marks were recorded on a bespoke form (Figure 2). However, this time only one of the examiners was independent, the other being the Project Leader, who facilitated discussion and provided reassurance to any candidates new to this form of assessment. Often, as illustrated in Figure 2, students did not recognise the significance of their contribution or were too modest in their claims and so the format of the examination provided an opportunity for the project leader to comment supportively on his/her contribution.

Figure 2: Viva Assessment Form

\begin{tabular}{|c|c|c|}
\hline \multicolumn{3}{|c|}{$\begin{array}{l}\text { LLB (HONOURS)/BA COMBINED HONOURS PROGRAMMES } \\
\text { CEDRM-UK PROJECT PRESENTATION: VIVA REPORT }\end{array}$} \\
\hline \multicolumn{3}{|l|}{ Candidate Name: $\mathrm{YY}$} \\
\hline \multicolumn{3}{|c|}{$\begin{array}{l}\text { Criteria for Assessment and Allocation of Marks } \\
\text { Vivas will take the form of an interview about your contribution to the project. } \\
\text { We may have some specific questions arising from your portfolio about your } \\
\text { contribution. } \\
\text { The viva is worth } 20 \% \text { of the mark and will be assessed according to the } \\
\text { University Assessment Criteria'. } \\
\text { Remember the viva is designed to give you maximum opportunity to outline } \\
\text { and evaluate your contribution to the project, so arrange your folder } \\
\text { intelligently to demonstrate this. Include all you have done - interviews, statute } \\
\text { evaluation, reading, conference attendance, presentations etcetera. }\end{array}$} \\
\hline \multicolumn{2}{|c|}{$\begin{array}{l}\text { Question/Comments } \\
\text { Question 1: Explain how you organised your Folder } \\
\text { A first class answer: clear rationale for organisation of folder; demonstration of depth of } \\
\text { understanding of subject and requirements of a research project }\end{array}$} & $\begin{array}{l}\text { Marks } \\
7\end{array}$ \\
\hline \multicolumn{2}{|c|}{$\begin{array}{l}\text { Question 2: Critically talk through your contribution to the whole project } \\
\text { - Less analytical than the other answers, nevertheless sufficient critical awareness and } \\
\text { demonstration of outcomes to satisfy } 2: 1 \text { criteria } \\
\text { Comment on finding being part of team due to being a shy person demonstrated awareness } \\
\text { of own shortcomings } \\
\text { Demonstrated good record of contribution to team: volunteered to compile the } \\
\text { presentation; took an active part in setting up equipment at trustees meeting because knew } \\
\text { others were too nervous to do so; agreed to do the foundation work on the GAD Advocacy } \\
\text { Service even though key interest was consent and confidentiality and the IMCA. }\end{array}$} & \\
\hline \multicolumn{2}{|c|}{$\begin{array}{l}\text { Question 3: What have you learnt from doing the project: knowledge and } \\
\text { methodology? } \\
\text { Demonstrated a developed critical understanding of the learning outcomes of the project } \\
\text { Comment on learning that preparing a report is hard work was supported by clear } \\
\text { demonstration of the reasons for this: difficulties of deciding on an appropriate } \\
\text { methodology for empirical research; the need to meet the fieldwork objectives; the } \\
\text { requirement of impartiality }\end{array}$} & \\
\hline \multicolumn{2}{|c|}{$\begin{array}{l}\text { Question 4: Where do you think the project should go from here? } \\
\text { - An excellent answer demonstrating a clear understanding of the limitations of } \\
\text { candidate's own foundation project } \\
\text { Candidate identified four 'avenues' to pursue: } \\
\text { 1. Some research into the effectiveness of the Code of Practice in regulating the } \\
\text { 2. Examination of the raining given to IMCAs and Advocates } \\
\text { 3. Study of the role of the doctor under the Mental Health Act } 2005 \\
\text { 4. Fieldwork on the other IMCA services as the candidate was only able to examine } \\
\text { one in the time allotted }\end{array}$} & \\
\hline \multicolumn{3}{|c|}{ AVERAGE MARK } \\
\hline \multicolumn{3}{|c|}{ 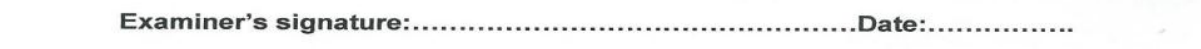 } \\
\hline \multicolumn{3}{|c|}{ 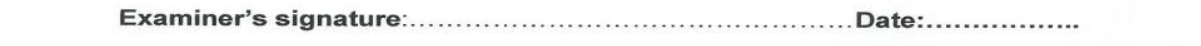 } \\
\hline \multicolumn{3}{|l|}{$\begin{array}{l}\text { CEDRM-UK Project Law } 1108 \\
\text { Law Department, University of Greenwich }\end{array}$} \\
\hline
\end{tabular}


The grounded theory model of 'research-based learning' imposes an obligation on the project leader/course tutor to ensure that the aims of the project are fulfilled. One of the briefs of both the international and the community project was to collate data relating to disability and the law in the United Kingdom and in the Borough of Greenwich respectively. As late as 2010, much of the data collected was in paper form and most students did not have access to scanning facilities. The students were, therefore, required to assemble their data in folders, most of which is now part of an electronic Disability Law database, which, once all copyright issues have been addressed, it is intended will be available on the university intranet. Though the viva is almost exclusively part of the English postgraduate curriculum, it seemed in this instance the most effective mechanism for ensuring that all the data was collated and considered.

\section{Conclusion: the importance of research-based learning in the undergraduate curriculum and the role of the grounded theory team project model}

Healey and Jenkins reported that "international research evidence strongly supports the idea...that at present many undergraduate students feel, in Brew's $(2006,52)$ powerful phrase, "at arm's length" from the university research community and do not see themselves as stakeholders in that research". $(2009,20)$ The opposite has been true of the members of the CERMP and the community project teams, who have defined and taken ownership of their projects from the start. Team members, as individuals, took themselves far beyond the barriers of the undergraduate curriculum - one student, for example, extending her project to empirical research into transport provisions for disabled people in Italy, another organising a conference with disabled students at Lille University. Furthermore, as teams, they rose collectively to whatever challenge was presented, sometimes to the initial consternation of the team leader: one project team, for example, accepted an invitation to the Cabinet Office to discuss their project, while the first team gave a very well-received presentation of their findings at the 2004 Socio-Legal Studies Association Conference. More fundamentally, the empirical nature of their research has indeed led to the "reconceptualization of the law" and moves to stimulate change. To give two examples, long before a human rights model of disability became a mainstream concept, respective CERMP research teams were arguing its importance in public fora, while the decision of a member of the first undergraduate team to examine the treatment of disabled prisoners highlighted a "marginalised group" of people whose rights had hitherto been ignored and his work, and that of subsequent teams, led to a contribution in an international book on developments in Disability Law (Rioux, Basser and Jones 2011).

The practical limitation of the grounded theory team project model outlined in this study is that any one project can, almost by definition, only be open to a relatively small number of students each year, though, depending on staff resources more than one project can be run at any one time. Nevertheless, it does much to remedy what has been identified as the shortcomings of the final year dissertation experience (the curriculum's alternative research project) "generally that of a written account that is only read by the student, the supervisor and the second marker...(which) may not be the most effective way of making a student part of a community of disciplinary research practice." (Healey and Jenkins, 2009, 20). An extract from the AMR for the 2004-5 project demonstrates how much the students, even as 
undergraduates, felt part of the research community: "Particularly important had been the presentations they had done, especially the team presentation to the SLSA Annual Conference in Glasgow in April. Not only had they needed to raise their standard above the normal expectation for undergraduate work, but they had benefited greatly from attending the conference, hearing papers and talking informally to other presenters." In an email approving the marks for the 2008-9 Project team, the External Examiner commented on "the enormous effort your students go to ... produce such interesting and valuable work." Later, at the Subject Assessment Panel, she again praised the course as "an example of value added".

Perhaps, more importantly, the presence of such a course in the undergraduate curriculum provides a vehicle for 'research-based learning' leading to a much deeper understanding of the relevant academic discipline, enhancing not only the individual student's skills and academic performance but, in addition, providing a service to the wider community through the project's findings. "John Bowater, GAD's Senior Advocate, commented at the research conference on the high level of the 2008-9 team's contribution and the value of the project in raising awareness of the legal issues relating to disability." (CERMP AMR 2009) Moreover, a theme often repeated in the student feedback was the positive effect the 'research based learning' had on their performance in their other courses. Feedback like this reported in the CERMP 2005 AMR was common: "All four ... believed that their involvement in this course had enabled them to raise their performance in their other third year subjects."

One practical solution to the resources issue identified above would be to unite individual team projects under one course with a common assessment regime, a strategy which the School of Law is currently trialling as a means of providing a Level 6 option "to give the student a direct practical experience through law in practice" (Law 1149: Pro Bono (Placement) Course Specification). It would also go some way to meet the former Chief Executive of the Higher Education Academy's call at the 2008 Department of Innovation, Universities and Skills' Debate on the Future of Higher Education for "new models of curriculum" that "should all ... incorporate research-based study for undergraduates (to cultivate awareness of research careers, to train students in research skills for employment, and to sustain the advantages of a research-teaching connection in a mass or universal system)." (Paul Ramsden, 2008, 10-11, quoted in Healey \& Jenkins 2009, 5).

\section{References}

Boyer Commission on Educating Undergraduates in the Research University (1998) Reinventing Undergraduate Education: a Blueprint for America's Research Universities. Stony Brook: State University of New York at Stony Brook. [Online]. Available at: http://www.niu.edu/engagedlearning/research/pdfs/Boyer_Report.pdf (Accessed 30 April 2013).

Healey, M. \& Jenkins, A., (2009) Developing Undergraduate Research and Enquiry, The Higher Education Academy. [Online]. Available at:

http://www.heacademy.ac.uk/assets/Documents/research/DevelopingUndergraduateResear chandlnquiry.pdf (Accessed 29 April 2013). 
Hellum, A. \& Stewart, J. (editors) (1998) Pursuing Grounded Theory in Law: South-North Experiences in Developing Women's Law. Harare: Mond Books.

Higher Education Academy Engineering Subject Centre (2013) Deep and Surface Approaches to Learning. [Online]. Available at: http://exchange.ac.uk/learning-and-teachingtheory-guide/deep-and-surface-approaches-learning.html (Accessed $21^{\text {st }}$ September 2013).

Kerrigan, K. \& Murray, V., (editors) (2011) A Student Guide to Clinical Legal Education and Pro Bono, Basingstoke: Palgrave Macmillan.

Kiley, M., Boud, D., Manathunga, C. \& Cantwell, R. 'Honouring the Incomparable: Honours in Australian Universities' Higher Education (2011) 62:619-633.

Laycock, A., (1996) The Role of Women's Law in Zimbabwe: From Legal Activism To African Jurisprudence, (LL.M Dissertation) University of Warwick.

Maboreke, M., (1990) 'Introducing Women's Law', Stewart, J \& Armstrong, A. (editors) Women and Law in Southern Africa Vol 2: The Legal Situation of Women in Southern Africa University of Zimbabwe Publications.

Macduff, A., (2005) 'Deep learning, critical thinking and teaching for law reform' Legal Education Review. Vol.15, no.1 \& 2, 2005. pp. 125-35.

Phillips, E., Clarke, S., Crofts S., and Laycock, A. (2009) 'Exceeding the boundaries of formulaic assessment: innovation and Creativity in the Law School', The Law Teacher, Vol.44 No.3, 334-364.

Rioux, M., Basser, A. \& Jones, M. (2011) Critical Perspectives on Human Rights and Disability Law. Leiden: Brill.

Strauss, A., \& Cobin, J. (1998) Basics of Qualitative Research: Techniques and Procedures for Developing Grounded Theory. California: Sage Publications.

Wellington, J., (2011) 'Supporting students' preparation for the viva: their pre-conceptions and implications for practice' Teaching in Higher Education Vol. 15, No. 1, February 2010, 71-84.

\section{Author Biography}

Angela Laycock is Senior Lecturer in Law at the University of Greenwich. Angela's main research interest is in the potential of grounded theory as a vehicle for teaching in higher education and as an analytical tool in empirical legal research. 